asimismo a aventuras caballerescas y a historias clásicas y, sobre todo, a actualizar éstas con toques decorativos de cortesanía y caballería medieval. Ya el benemérito A. Paz y Mélia llamó la atención sobre las palabras cardiamo en relación con la ninfa de la fábula ovidiana que sirve de marco a la defensa de las mujeres en el Triunfo de las donas (Obras, Madrid, 1884, p. 431). Compenetrado con la manera de Ovidio, Rodríguez del Padrón da como nombre propio al personaje metamorfoseado en árbol el nombre común del árbol -el amante desdeñado Aliso, convertido en el árbol así llamado, sigue la pauta de Jacinto, Mirra, Narciso-, mientras el personaje, siempre femenino, metamorfoseado en fuente, recibe un nombre griego, no significativo en latín o en romance -la enamorada esquiva Cardiama, convertida en fuente, sigue la pauta de Aretusa, Biblis, Dirce, Níobe. El texto de la ed. cit. del Triunfo de las donas trae, en verdad, Cardiana (pp. 124 y 125) y no Cardiama, sin indicación de variantes, y lo mismo el de la Sátira de felice e infelice vida del Condestable don Pedro de Portugal, en un pasaje alusivo (Opúsculos literarios de los siglos xiv a xvi, ed. A. Paz y Mélia, Madrid, 1892, p. 83), pero la glosa a este último pasaje, escrita por su mismo autor, dice Cardiama (apud Rodríguez del Padrón, Obras, pp. 430-431). Es verosímil que, siendo - ana sufijo tan frecuente en la composición de nombres propios femeninos como es raro -ama, la glosa de la Sátira haya conservado la leElio difficilior, derivada de la expresión de ternura con que doña Angelina de Grecia evocaba la patria lejana.

Renée Toole Kahane María Rosa Lida de Malkiel

Urbana, Illinois.

\title{
EL CANCIONERO LÍRICO JUDEO-ESPAÑOL DE MARRUECOS
}

Se sabe que los judíos españoles de Marruecos conservan, además de sus romances, canciones y textos líricos tradicionales. Su cancionero habia sido, hasta ahora, menos explorado que su romancero. Una Endecha publicada en $190_{5}$ por Menéndez Pidal y Benoliel, una pieza del conocido Catálogo del romancero judio español de Menéndez Pidal (el núm. 141 que es otra Endecha; el Romance para bodas del núm. 136 no es marroquí, sino oriental), algunas canciones de bodas publicadas por BENolieL en su estudio sobre "El dialecto judeo-hispano-marroqui" (BAE, 14, 1927, pp. 369 ss.), unas referencias muy incompletas a otra canción de boda en el apéndice de mi colección $(R F H, 6,1944$, p. 355), algunos textos publicados aisladamente en los Romances de Tetuán de Larrea Palacín (2 vols., Madrid, 1952; su núm. CiI es el 141 del Catálogo, ya mencionado; el cvn, Ester y Asuero, es una cantilena religiosa; el cxxv en su segunda versión es canción de boda, -la primera es un texto del todo distinto, que sólo ha sido contaminado por éste), son todo cuanto había sido dado a luz de ese rico patrimonio. Arcadio de Larrea Palacin y Manuel Alvar han llenado hace pocos años gran parte de ese vacío. El primero ha pu- 
blicado, como continuación de sus dos tomos de romances tetuaníes, una colección de "canciones rituales" de la misma procedencia ${ }^{1}$. Esas canciones (que en realidad son, en su gran mayoría, canciones profanas) van clasificadas en dicha colección según las circunstancias de la vida en que se cantan. Larrea Palacín nos proporciona datos interesantes sobre el ceremonial que usan los judíos españoles en las fiestas y los acontecimientos familiares. En cuanto a los textos, son, en primer lugar, canciones de boda ( 71 versiones de unas 50 canciones), a menudo muy hermosas, $y$, según toda probabilidad, antiguas y anteriores a la influencia de la España mo. derna en Marruecos. Las canciones relacionadas con el nacimiento o la niñez son menos ( 4 únicamente). Los cantos fúnebres consisten en tres versiones de la Endecha ya publicada por Menéndez Pidal-Benoliel, y dos fragmentos aislados. Siguen varios cantos de fiestas: romances religiosos con mezcla de hebreo, poemas y traducciones al ladino de textos litúrgicos correspondientes a las distintas fiestas y conmemoraciones religiosas (27 textos). Sigue una serie de 6o "coplas de columpio", de las cuales muchas son seguramente de origen peninsular moderno (son los únicos textos de la colección que tienen ese carácter). Por último se publican cantos de Tis'a be- $\mathrm{Ab}$ ( 9 del mes de $\mathrm{Ab}$ ), o sea tres cantos fúnebres sobre la destrucción del templo de Jerusalén, que se conmemora ese día. La colección se termina con un fragmento aislado, núm. 172, y dos versiones del conocido romance de Don Gato. Larrea anuncia (p. 10) un cuarto volumen, de Canciones varias (resto de las canciones y romances recogidos mientras tanto). El volumen publicado, a pesar de repetir los defectos de los dos anteriores, y del poco cuidado que se advierte muchas veces en la transcripción de los textos recogidos, es el primer cancionero que reúne el conjunto de la tradición marroquí.

Por su parte, Manuel Alvar publicó un estudio, ilustrado con muchas citas, sobre las canciones de boda de los judíos españoles de Marruecos². Este estudio incluye valiosos informes sobre la bibliografía anterior del tema, sobre las costumbres nupciales españolas y judías y sobre los ritos de las bodas judeo-españolas en Marruecos. Alvar estudia después la versificación de las canciones de boda marroquíes, comparándola con las formas métricas españolas, y también los temas y motivos de esos cantos y sus correspondencias en la tradición lírica de España. No todas las canciones citadas por Alvar figuran en la colección de Larrea. El mismo Alvar ha publicado en otra parte el texto completo de cinco de ellas, todas muy bonitas y con exquisito sabor de lírica española antigua ${ }^{3}$. Además, ha dado a luz una importante colección de cantos fúnebres ${ }^{4}$, endechas o endichas ${ }^{5}$ en judeo-español marroquí, también Ilamadas oinas o en los últimos tiempos saetas: en total doce poemas en versiones de Larache (más una versión de Tetúan para dos de ellos), a los cuales precede

1 A. de Larrea Palacín, Cancionero judio del Norte de Marruecos. III, Canciones rituales hispano-judias. Instituto de Estudios Africanos, Madrid, 1954.

2 Manuel Alvar, "Cantos de boda judeo-españoles de Marruecos", Clav, nov.-dic. 1955, pp. 12-23.

3 Antología de la poesía española de tipo tradicional, ed. Dámaso Alonso y JosÉ M. Blecua. Madrid, 1956 , pp. 495 ss., núms. $497^{-5}$ o1.

* Manuel Alvar, Endechas judeo-españolas. Universidad de Granada, 1953.

s También desdichas, según Larrea Palacín, Canciones, pp. 8 y 131. 
un estudio erudito sobre el "planto" de muerte en la doble tradición bíblica e hispánica, y un esbozo de historia de la endecha literaria en España desde sus orígenes medievales, con la indicación de sus motivos más frecuentes, y en particular de las formas y los temas de la endecha judeoespañola.

Toda esa tradición lírica de los judios españoles de Marruecos, notable por su riqueza y su valor poético, que apenas se nos descubre hoy, exigiría ser estudiada detenidamente y situada en el conjunto de la tradición hispánica. Alvar ha dado comienzo a ese estudio, que irán prosiguiendo los conocedores de la antigua lírica de España. Quiero limitarme aquí a hacer unas observaciones sobre los cantos fúnebres ya recogidos. Los recolectores siempre han tropezado con dificultades insalvables al querer explorar esa parte de la tradición, debido a la poderosa superstición que prohibe cantar o repetir canciones de duelo en tiempo normal, so pena de atraer desgracias. Ya los romances destinados al 9 de Ab (en general son los que cuentan una muerte trágica) son muy difíciles de conseguir (véanse listas de esos romances en Larrea Palacín, Romances de Tetuán, $\mathrm{I}, 27$, y en los comentarios del núm. xLV de mi colección, RFH, 6, I944, pp. 323-324): no son más que romances narrativos, y sin embargo ninguna de mis informadoras se atrevió a recitármelos; yo creía mi cosecha terminada desde hacía mucho tiempo, cuando los recibí por correo, copiados a mano: habían esperado al mismo día del 9 de $\mathrm{Ab}$, el único en que se pueden recitar impunemente, para transcribirlos y enviármelos; y más tarde, al mostrar mi colección en Orán, oí juzgar con severidad a las personas que habían tenido el mal gusto de comunicármelos. Imagínese cuán difícil será recoger cantos fúnebres propiamente dichos $^{6}$. Yo no lo he logrado nunca; mejor dicho, apenas me atreví a pedir tal cosa. Hay que felicitar, pues, al profesor Alvar por el magnífico resultado de su investigación. Nos dice él mismo (p. I3) cómo ha procedido: después de toda clase de fracasos, dio con una "vieja plañidera", a quien probablemente ya no impresionaban aquellos cantos por haberlos entonado multitud de veces, o cuyas inhibiciones tradicionales habían sido debilitadas por el ambiente del Marruecos moderno.

Los primeros textos (I-VI y vin-Ix) de Alvar son, más bien que textos literarios propiamente dichos, unas lamentaciones patéticas, muy irregulares en su versificación (Alvar hace esfuerzos meritorios para caracterizar los tipos de versos y estrofas que los componen, sin conseguirlo siempre); el llanto se desarrolla en ellas con la repetición de fórmulas análogas, a lo largo del poema, en grupos de versos paralelos; las mismas fórmulas, combinadas o utilizadas de diversos modos, se reproducen continuamente de un texto a otro: así, por ejemplo, un dístico con el primer verso que dice "Se van los novios chiquitos", o ". . Ilos maridos chicos" o "mocitos y arasbas ("mozas')", y el segundo "y no crían a sus hijos" o "y no hacen alegría" o "vacían su casa y su lugar", vuelve a aparecer en los textos II, III, IV, v, Ix. Otro, del tipo "Los viene el dolor rabioso, / no llevan cura

- Ia dificultad es igual en Oriente. Me ha contado Alberto Hemsi, editor de las Coplas sefardies y recolector de un riquísimo romancero-cancionero sefardí oriental, hasta ahora inédito, que sólo pudo conseguir algún canto fúnebre haciendo intervenir la elocuencia y autoridad de rabinos o personas principales para convencer a las poseedoras de la tradición. 
ni melecina" se encuentra en los núms. IV, VI, viII. Esos textos monótonos son, en verdad, impresionantes: conmueven por la misma pobreza y violencia de sus recursos, y su aspecto a veces estragado, como si los hubiera arruinado el dolor, aumenta quizá su fuerza fúnebre. Hay que notar que ese tipo de endechas es el que con más dificultad han conseguido los recolectores, pues ha quedado ignorado, por lo visto, hasta el libro de Alvar; en el cancionero de Larrea, sólo dos fragmentos cortos, los núms. 79 y 8 o de la colección, parecen pertenecer a esa categoría. Ello se debe a que esos textos son los verdaderos llantos de muerte usados tradicionalmente, en los cuales la desgarradora expresión del dolor sólo admite recursos literarios sencillísimos. Son y recuerdan la muerte, y por eso son los que inspiran más miedo.

El texto vil muestra una combinación curiosa de ese género con otro, pues empieza por ser una lamentación religiosa sobre la destrucción del Templo y el saqueo de Jerusalén, a la que sigue luego el llanto fúnebre privado (supuesto discurso de una hija muerta a su madre). Esa forma híbrida del texto parece tradicional, pues se halla igual en la versión Larrea (núm. 170; compárese con los cantos de duelo puramente religiosos sobre la destrucción de Jerusalén que figuran en la misma colección, núms. 168 y 169). El diálogo del muerto o la muerta con su madre es un motivo que también aparece en las endechas $\mathrm{v}$ y vi de la colección de Alvar.

Con los núms. $\mathrm{x}$ al xiI pasamos a una clase de poemas muy distinta. Son textos literarios antiguamente conocidos, conservados por la tradición marroquí. El núm. x, sobre todo, es notable: es la endecha que más arriba mencionamos y que han publicado hace medio siglo Benoliel y Menéndez Pidal ( $R A B M, 1905$, pp. 128 ss.). Esta composición, que muestra el espíritu y los temas de la Edad Media en sus últimos tiempos, cuenta en forma dialogada cómo la muerte viene a buscar a un caballero, lo reclama a su portero, y por fin lo decide a irse con ella después de un largo y terrible debate. Menéndez Pidal colocaba ese texto entre los "elementos originales de inspiración propiamente hebraica" (p. 128), y Benoliel escribía: "Esta endecha... es de composición hebrea" (p. 131, n. I). Hay que abandonar por completo esa opinión después del estudio de Alvar, quien señala, en primer lugar, la identidad de los cuatro primeros octosílabos ("Muerte que a todos convidas, / dime qué son tus manjares. / Son tristuras y pesares / y altas voces doloridas") con el principio de un Razonamiento atribuido a Juan de Mena, que fue publicado hace tiempo por Foulché-Delbosc (RHi, 9, 1902, pp. 252-254). Además, todo el diálogo de la Muerte con el portero y luego con el caballero, reproduce indiscutiblemente unas anónimas Coplas de la Muerte que figuran, según indica Alvar, en un pliego del siglo $\mathrm{xvI}^{7}$ en el cual va impreso también el Razonamiento. Alvar nos ofrece una versión completa de esa endecha, recogida en Tetuán (pp. 83 ss.) y otra, muy acortada, de Larache (pp. 93 y 94); reproduce también (pp. 89-91) las variantes de la versión Benoliel, (desgraciadamente con una numeración inexacta de los versos en la última parte), y (pp. 102 ss.) el texto de las Coplas de la Muerte según el pliego

${ }^{7}$ Cf. p. 196; ese pliego, después de haber sido propiedad del librero valenciano Salvá, está hoy en la B.N.M. 
antiguo ${ }^{8}$. El lector podrá comprobar la poca diferencia que existe entre las distintas versiones marroquies, la de Benoliel, las de Alvar y las tres de Larrea (núms. 76,77 y 78 de su colección: la segunda, acortada; la tercera manuscrita e inacabada); la semejanza es casi completa entre todas ellas, salvo huecos y desplazamientos ordinarios en esa clase de textos. Se podrán comparar, además, las versiones judias con el texto antiguo (27 estrofas de 8 octosilabos). El texto marroqui, en su primera parte, sigue con bastante fidelidad las antiguas coplas I-vir y x-xr; luego se independiza, exceptuando algunos motivos sacados de las coplas xv, xvI, xxn, para desarrollar una conclusión del diálogo muy superior en belleza e intensidad a los discursos edificantes que terminaban la pieza antigua. Es particularmente notable la evocación de una lucha entre el caballero y la Muerte (en el estilo de aquella que cuentan las versiones marroquíes de La Muerte ocultada, entre Bueso y el Huerco: cf. Menéndez Pidal, Catálogo, 75, y mi núm. xLVI). En nuestra endecha, se interrumpe por primera vez el diálogo en este lugar e interviene el narrador: "Arzara la mano el Huerco, / hirióle sus lindos ojos; / presto demandara el rey / a su madre los antojos". (LARREA 76, versos 10r-104; pasaje parecido en Larrea 77, Alvar xa, Benoliel). Este pasaje narrativo parece haber surgido de unas palabras del caballero en la fuente antigua ("Ya no veo de mis ojos, / dolor de mi mancebía, / dadme acá unos antojos...", vv. 173 ss. de las Coplas). Más lejos vuelve a intervenir el narrador sobre el mismo tema, cortando otra vez el diálogo: "Ay qué árbol tan florido / como el azahar en flor, / batallando en el Huerco / no se muda de color" (Larrea 76, vv. 150-153; igual en Larrea 78, Alvar x $a$ y x $b$, Benoliel). Además de ese motivo, figuran en la segunda parte de la endecha marroquí varios temas a veces vecinos de los que evocan las Coplas, y a veces ausentes de ellas (por ejemplo, la consulta del caballero al Huerco sobre cuál es la mayor de las penas de la muerte, o la declaración del Huerco, que tiene que llevarse cien almas antes del amanecer, y la consigunente discusión sobre si será la del caballero la primera de ellas, o la última). Alvar no nos dice cómo puede haberse elaborado ese fin del poema marroquí, tan distinto del de las Coplas del pliego antiguo.

$\mathrm{La}$ aparición de ese poema en la moderna tradición marroquí plantea un problema bastante difícil de resolver. Al contrario de lo que se puede suponer con respecto a otros poemas extensos, también de origen libresco (largos romances juglarescos, moriscos, vulgares), conservados oralmente por los judíos españoles de Marruecos a partir de impresos cuya introducción en Marruecos parece ser reciente, ¿habrá que admitir que el tex to impreso de esta endecha ha pasado a África en tiempos tan antiguos como el siglo xvi? Las versiones marroquies, en la parte de su texto que sigue más fielmente el de las Coplas, no sólo están alteradas en el detalle de la expresión (como sucede siempre, y casi inmediatamente, a los textos literarios adoptados por la tradición oral), sino que aparecen a veces modificadas, en cierto modo rehechas de verso en verso, como por una acción tradicional muy profunda. Además, la refundición completa de la segunda parte, probablemente con materiales sacados de otra fuente

$\therefore$ Reproduce, además, pp. 97-98, las variantes del Razonamiento en ese pliego con relación al texto que publicó Foulché-Delbosc. 
desconocida (?), podría sugerir la misma conclusión. Esos argumentos, claro está, no son decisivos, pues tales procesos se producen, a veces, en plazos sorprendentemente cortos. Por otra parte, muchos pasajes reproducen el texto antiguo casi literalmente, y con tantas alteraciones de detalle que parece difícil imaginar que un texto largo, estropeado en esa forma, y más de una vez vuelto ininteligible por esa mezcla de fidelidad y corrupción, haya podido vivir intacto durante siglos. No es del todo imposible admitirlo, suponiendo, eso sí, que han mediado muchas veces y largo tiempo copias escritas en el curso de la tradición. Las Coplas y el Razonamiento no se han vuelto a imprimir, que yo sepa, entre el siglo xvi y su descubrimiento por eruditos modernos. Si hubiera existido alguna reimpresión de esos poemas, y si los judios de Marruecos hubieran podido conocerla durante el siglo xix, el asunto resultaría más claro. Dejo que otros, más informados que yo, resuelvan este punto.

No se plantea tal problema a propósito del texto xI de la colección Alvar (=Catálogo, 141; LARreA, Romances CIII, versiones 211 y 212). Este corto poema hexasilábico ("Parióme mi madre /en una noche oscura") es un lamento melancólico sobre el propio destino más bien que un llanto fúnebre propiamente dicho. Alvar, en unas páginas eruditas, reproduce un texto de ese poema publicado en 1573, y un fragmento de él, que introdujo Lope de Vega en Las famosas asturianas. Piensa poder demostrar, comparándolo con textos poéticos del siglo xv, que ese poema existía en España antes de la expulsión de 1492, y que las versiones del siglo xvi proceden de una tradición anterior. Sea como fuere, el estilo de las versiones marroquíes, su grado de independencia con relación a los textos antiguos y la brevedad del poema, concuerdan perfectamente con la hipótesis de una larga tradición oral.

El texto xn (quejas y muerte de una muchacha abandonada por su amante) procede de un poema de Juan Menéndez Pidal, Lux aterna, publicado en 1889 y muy pronto popularizado en España, donde se han recogido ya varias versiones orales de él. Alvar reproduce (pp. 197 ss.) el texto original del poema. La distancia entre la versión oral marroquí -a decir verdad, muy mediocre- y el texto impreso es muy grande a pesar de ser indiscutible la filiación. No conozco las versiones orales peninsulares (Alvar sólo menciona su existencia, sin dar noticia de ellas), y por lo tanto ignoro si la marroquí es resultado de una elaboración oral original o si es simple importación española en Marruecos. En todo caso, ese poema sentimental, de carácter tan moderno, demuestra la capacidad de absorción de la tradición marroquí; su texto prueba la rapidez (unos cincuenta años, cuando más, en este caso) con que la transmisión oral puede alterar y refundir profundamente los textos que maneja.

Pall BÉnichou 